\title{
OFFICIAL USE OF KEY PERFORMANCE INDICATORS IN THE EDUCATION SECTOR: CASE OF SAUDI ARABIA
}

\author{
Monera G Alkhaldi a \\ Prof. Yoser Gadhoum b \\ ab Prince Mohammad Bin Fahd University, Alkhobar, Saudi Arabia \\ Corresponding email: mnqaldi@edueast.gov.sa
}

\begin{abstract}
The key to an organization`s success is good management information that allows the organization to monitor and evaluate the progress it has made. Organizations are in a race to achieve their goals and to increase productivity in many ways. The ministry of education of Saudi Arabia (the MOE) is one such organization. This paper analyzes key performance indicators (KPIs) as tools which the MOE can use to measure work. The goals for a particular KPI may change as the organization's goals change, or as it gets closer to achieving a goal. The purpose of this thesis is to provide usage of one source which reduces costs and saves time. To reach this result, the thesis will start with three questions. The thesis is split into theoretical and practical parts. Drawing on literature, the theoretical part discusses main tools of electronic KPIs, including the Noor website, which the MOE already uses. The practical part includes the results and analysis of questionnaires. The collected information from supervisors and school managers, who work in the MOE, contributed to the results.

The findings indicate that KPIs are important tools for measuring work, but that the MOE needs to improve in a few areas, specifically those relating to training and the amount of paper being used. The findings also show that Internet connection speed is too slow.
\end{abstract}

Keywords: Key Performance Indicator, KPI \& Education.

\section{Introduction}

At the beginning of this new millennium, education is becoming more and more important to a country's development. Accordingly, educational organizations must improve their performance. Many things in an organization are measurable. That does not make them key to the organizations' success. In selecting Key Performance Indicators (KPIs), it is critical to only choose factors that are essential to the organization reaching its goals. It is also important to keep the number of KPIs small so that everyones attention remains focused on achieving the same KPIs. In addition, KPIs are very important to educational supervisors' and schools managements determination of certain factors that are essential to the growth of their organizations and KPIs enable supervisors and schools managers to understand both where progress is being made toward strategic aims and the areas that need to be addressed. In recent years Saudi Arabia, a third world country, has significantly developed with regard to education in order to achieve its government goals, and to perform with strength. Seeing a positive impact from using KPIs in Saudi Arabia's higher education system gave the Ministry of Education in Saudi Arabia (the MOE) the needed motivation to use KPIs in basic education, for both educational supervisors and school management. Supervisors and school managers who work in 
the MOE have performed well using the Noor website to perform work over the Internet. This thesis will argue that KPIs are suitable for basic education and that using KPIs in basic education by adding an icon on the main website will save time and increase productivity. In order to successfully transition from using paper to using electronic documents, this study adopted both qualitative and quantitative methods to conduct the research. The study included focus groups, interviews, documentary analysis and questionnaires collected from supervisors in offices and from school managers.

\section{Literature Review}

Key performance indicators (KPIs) are very important tools in modern organizations. Many studies have argued the importance of KPIs to measuring results in companies in government as well as private sectors. KPIs developed from Western countries as the first group of tools for increasing educational efficiency and effectiveness. Countries in Asia have also used them. Middle Eastern countries, including Saudi Arabia, have used KPIs in their higher education systems. In 2014,the MOE started using KPIs as effective tools to improve the educational system for both supervisors in offices and school managers. One site included in this study is being used to help supervisors and school leaders to perform their work. There was no evidence that the system previously been used in Saudi Arabia or any of the Gulf countries.

However, researchers have different opinions on how to define KPIs. Some define KPIs as statistical measurements (Johnstone, 1981) while others stress the performance of organizations (Spee \& Bormans, 1992) or are strategies for the qualitative and quantitative measurement of organizations (Cuttance, 1990). KPIs can signify a single or multiple input, result or practice for evaluation and can take the form of figures, percentages, quiz marks, points of contribution or observations of student success (McEwen, 1995). One crucial consequence of the discussion of KPIs is that more nations have chosen to adopt accountability reporting systems that demand public institutions to measure and report their performance via shared and fixed measures. This system is principally applied in the United States (Burke \& Serban, 1998), the United Kingdom, Australia, the Netherlands, Finland, Denmark, Norway, Sweden (Cave et al., 1997) and Japan (University Council, 1998), Middle East countries such as Saudi Arabia mainly use KPIs in higher education.

No one has yet written about the need for unified regular measures in the MOE. This thesis argues that a single resource could be used to contribute to accountability, productivity, and quality improvement in education as well as, to help educational employees continue their work efficiently.

As all studies have found KPI can be defined as a group of factors that are crucial to determine the success and achievement of an organization by reflecting its performance. Educational KPIs can be defined as a class of performance measurement that is designed to professionally and efficiently evaluate the achievement of an organization as a whole, an organizations advancement toward its strategic goals, or a specific performance inside the organization. Based on the above reasoning, I formulated the following hypothesis:

Hypothesis 1: Would the connection between the Noor website and KPIs result in increased employees productivity?

This hypothesis is validated, if there is a positive relationship between employees productivity and the connection between the Noor website and KPIs. 
Asia Pacific Journal of Advanced Business and Social Studies

ISBN (eBook): 9780994365675 । ISSN : 2205-6033

Year: 2017 , Volume: 3, Issue: 2

A P I A R

Hypothesis 2: Do the employees use the system in an effective way?

This hypothesis is validated if there is a positive relationship between the systems usage and its effectiveness.

Hypothesis 3: Would the connection affect outcome?

This hypothesis is validated if there is a positive relationship between the connection and the outcome.

\subsection{Ministry of Education (MOE)}

Education has been one of the first and most prominent benefits accompanying the development of the modern State of Saudi Arabia. In 1925, the Directorate of Education was established. It was followed a year later by the Basic Instructions that laid the foundation for a centralized national system of government (Ministry of Education, n.d.)

The Ministry of Education is serving a free general education in schools, higher education and has a responsibility for museums and antiquities.

\subsection{History}

From the very formation of the Kingdom, education was seen to be of importance. One of the first acts of King Abdul Aziz was to convene an educational gathering in the Holy City of Makkah with a view to initiating the promotion and establishment of educational resources throughout the land. The Ministry of Education opened public education for everybody from primary level through universities and the budget of education is the highest in Saudi Arabia. It is allocated $25 \%$ of total budget expenditure in $2015(£ 37 \mathrm{bn})$. The government of Saudi Arabia set forth a strategy plan for 10 years which reflect the current situation and future needs. A percentage of GDP shown in next figure and we can understand that expenditure on education has been comparable if we see the average to other developed countries (World Development Indicators (WDI), 2007). Furthermore, Saudi education selected as a fast growth according of value of education development (2000-2004).

\subsection{NOOR Education Management System}

-Teachers, Principles, students, Parents, ...... etc.
-Easier services, Anytime, any where

-More satisfaction

- Provide Statistics, Reports \& KPIs about education

-At school, district, \& Kingdom wide level

-Better Quality

-Better planning

-More cost effective

- Provide full functionality of school administration for all K-12 schools in Saudi Arabia

- Efficiency \& effectiveness of the education system

- Accurate and timely data

- More transparent 


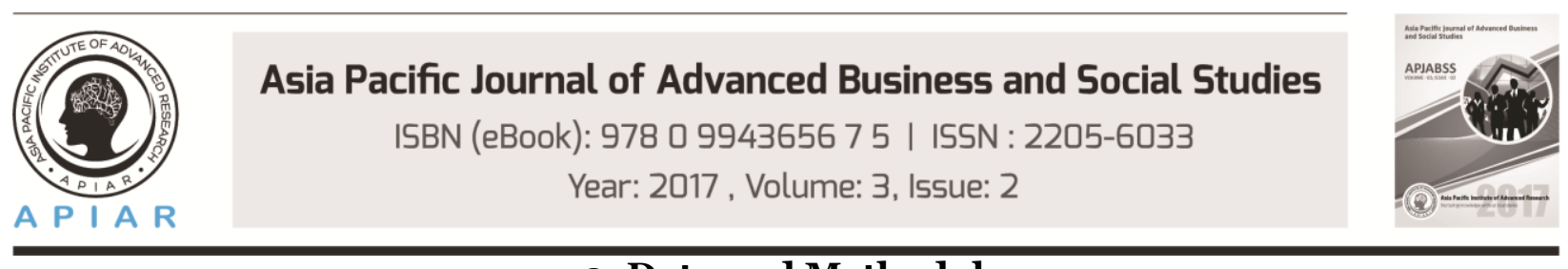

\section{Data and Methodology}

The data used in this paper are collected from various sources, including focus groups, interviews, documentary analysis and questionnaires that were answered by supervisors in offices and school managers. For three hypotheses, the survey is used. (Form2).

\section{Results and Discussion}

The results for my Hypothesis are reported in (Form2). The following is a summary. The largest number of respondents: spent a long time (4-5 hours) fulfilling the performance indicator requirements daily, and believed that the KPIs system focused on the development of performance concerning teachers, directors and supervisors. Most of the respondents said that using the KPI system improved employee performance by $20-30 \%$, this suggests that employees faced difficulties from different sources they used in their work. On the other hand, most of the respondents simply answered that they spent time (1-2 hours) working on the Noor website daily. The same number of respondents concluded that they will save time (1-2 hours) by using the new system to finish all their tasks. Furthermore almost all the respondents agreed that the new KPIs educational system should use electronic tools which would strongly require training and a high speed Internet connection. Finally, most respondents thought there was a benefit such as linking the two systems.

Form2: The results:

Position :

64\% supervisor

$36 \%$ Manager
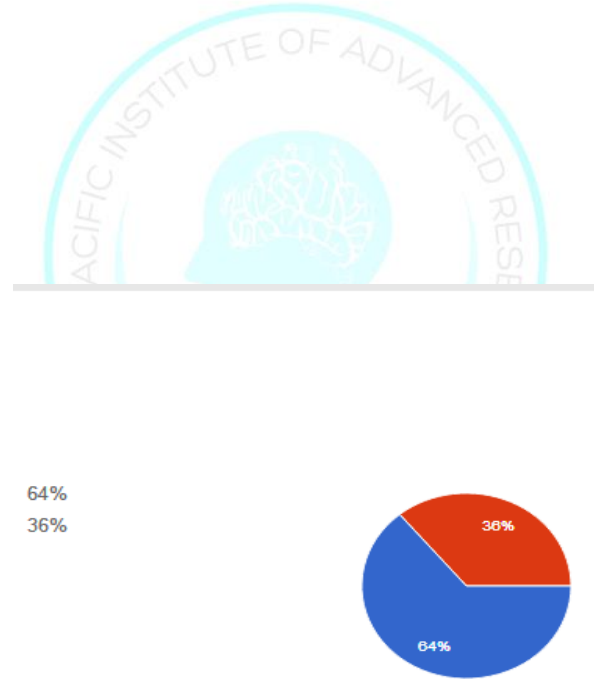

How many hours do you usually spend on working with the performance indicator requirements (daily)?

2-3 Hours 24

3-4 Hours 36

4-5 Hours 40 


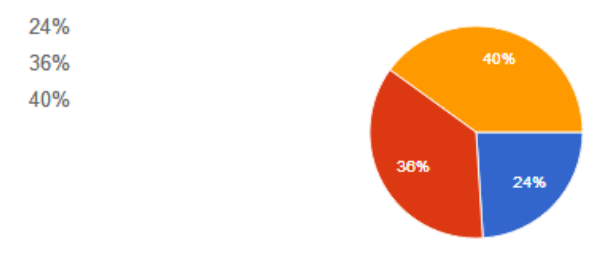

Do you think the system focuses on the development of performance concerning teachers/ directors/ supervisors?

73 Yes

22 No

5 I don't know

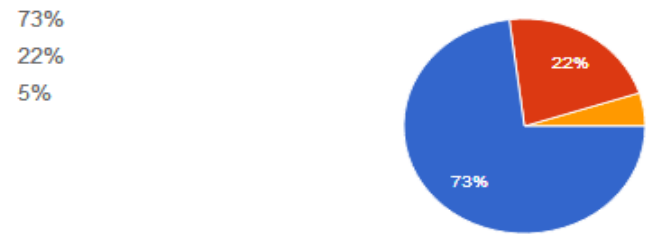

What percentage of progress added to the performance of your employees after applying the system (performance indicators)?

ᄂ $20-30 \% 41$

\. $40-50 \% 40$

こ $60-70 \% 19$

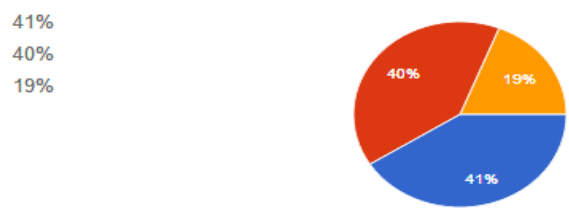

How many hours do you usually spend working on the website Noor (daily)?

1-2 Hours 65

3-4 Hours 29

4-5 Hours 6 


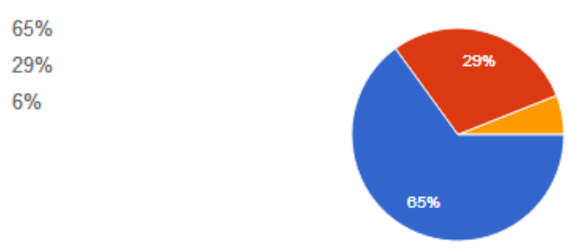

If the (performance indicators) system was connected to Noor website, how many hours are approximately needed to complete a regular day work in your opinion? Less than one hour 8

1-2 Hours 65

3-4 Hours 27

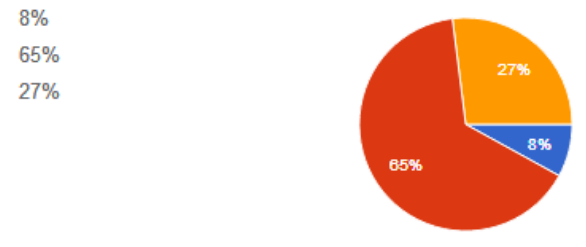

How would you rate your performance indicators before the new implementation? I have no information 42

$10-20 \% 42$

$30-40 \% 16$

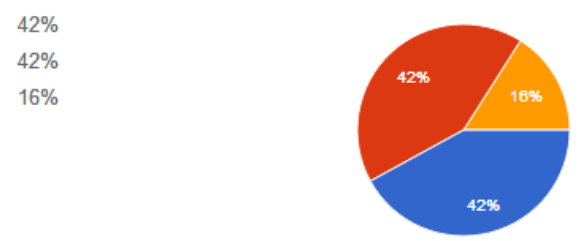

Have you been trained adequately before applying the performance indicators?

No 27

Yes 12

Not enough 61 


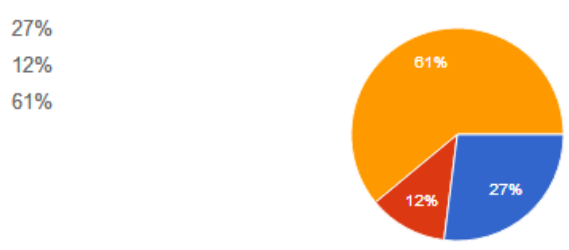

Do you consider your computer literacy as perfect?

Yes 86

No o

Slightly 14

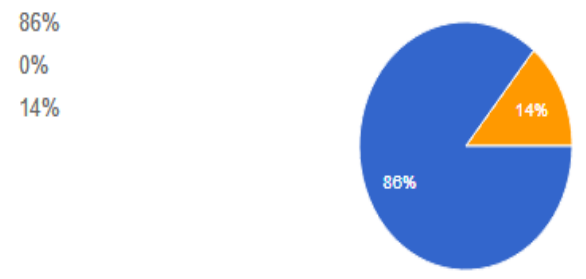

Have you ever used the website Noor?

Yes 97

No 3

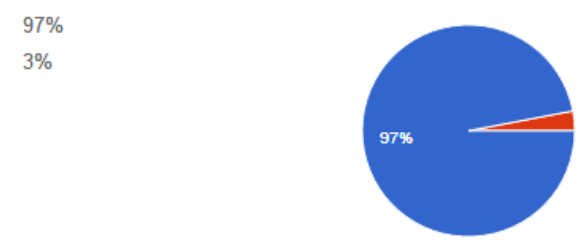

Rate the Internet in your work environment?

Excellent 11

Very good 26

Good 31

Low 32 


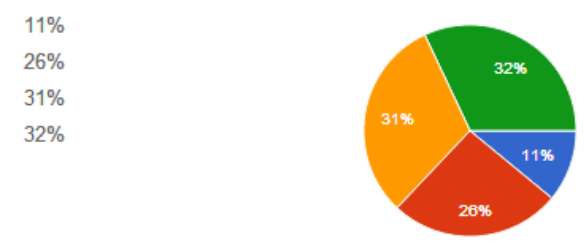

What benefit do you think of in linking the (performance indicators) system with Noor website?

Time saving 31

Productivity increase 9

Environment protection 5

All the previous answers 55

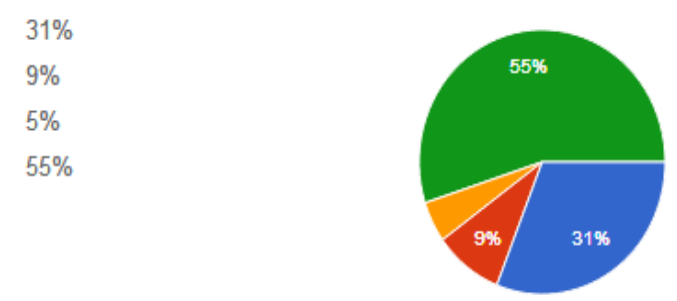

What are the main three difficulties you faced when applying the (performance

\section{indicators) system?}

1. Excessive usage of paper-work.

2. Feeble internet connection in the work place.

3. Insufficient training and time to end tasks.

\section{Conclusion}

Many theories suggest importance of using KPIs in educational organizations. In this research, I have formulated and tested three hypotheses related to using KPIs in Saudi schools and education offices:

The connection between Noor website and KPIs increase Employees productivity, the current system waste the employees efforts, and the new system affects the quality of outcomes. After the testing by using questionnaire, groups focus, meetings the employees who used the system and collecting data about the Ministry of Education in Saudi Arabia and the Noor website, I found that there is a positive relationship between employees productivity and the connection 


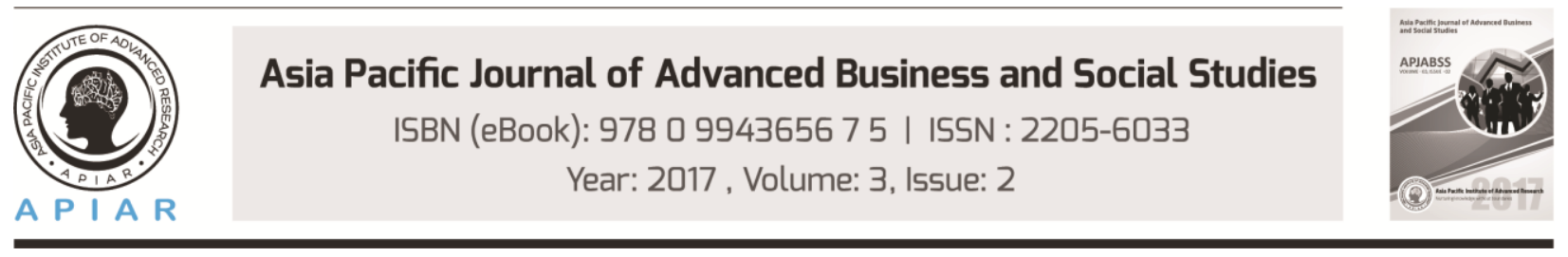

between the Noor website and KPIs, also there is a relationship between the current systems usage and its effectiveness, furthermore there is a positive relationship between the connection and the quality of outcomes that is meaning a KPI system in education should be applied via electronic tools which we will contact between Noor website and current KPIs tools and stop using paper forms, a high speed Internet connection would be necessary to insure perfection in performance at the workplace. To enhance quality and productivity all departments and offices should be included under the same system. Finally, this sophisticated system should be initially aimed at school managers and supervisors who receive a comprehensive training. I believe that the current KPIs Educational system focused on the development of performance concerning teachers, directors and supervisors who faced difficulties from different sources they used in their work, as well that KPIs system improved employee performance. On the other hand all employees used Noor website, this sustains the importance of linking the two systems to save time and increase their productivity. Furthermore this new system needed training and a high speed Internet connection. This implies that the KPIs system has a positive effect on employees productivity, effectiveness and the quality of outcomes. 


\section{Asia Pacific Journal of Advanced Business and Social Studies \\ ISBN (eBook): 9780994365675 । ISSN : 2205-6033 \\ Year: 2017 , Volume: 3, Issue: 2}

\section{References}

i. AkiyoshiYonezawa \& Kaiser, F., 2003. System-Level and Strategic Indicators for Monitoring Higher Education in the Twenty-First Century. s.l.:s.n.

ii. AL-Ghamdi, J., 2015. NOOR Education Management System, Saudi Arabia: Ministry of Education, Saudi Arabia.

iii. Arab Brains, 2013. Noor, The Education Management Information System. [Online] Available at: http://arabbrains.com/2013/05/02/noor-the-education-management-informationsystem-

iv. Bureau for Global Health, 2010. Guide for Assessment\& Quality Enhancement for Universities in the Islamic World. s.l.:s.n.

v. Cambridge Dictionary, 2015. Meaning of "key performance indicator". s.l.:Cambridge Dictionary.

vi. Chan, A. \& Chan, 2004. Key performance indicators for measuring construction success. Benchmarking: An International Journal, 11(2), pp. 203-221.

vii. KadarsahSuryadi, 2007. Framework of Measuring Key Performance Indicators for Decision Support in Higher Education Institution. Journal of Applied Sciences Research.

viii. $\quad$ Kerr, S., 2000. Key performance indicators as a policy implementation technique, Alberta: University of Alberta.

ix. $\quad$ Key Perfomance Indicators, 2014. The Balanced Score card Approach,Guidebook on KPIs, s.l.: s.n.

x. $\quad$ Manage, n.d. Manage. [Online]

Available at: http://www.manage.org.cn

xi. Ministry of Education, n.d. Noor, Ministry of Education. [Online]

Available at: https://noor.moe.gov.sa/Noor/login.aspx

xii. $\quad$ Public Record Office Victoria, 2015. Guideline 3,Key Performance Indicators. 1 ed. Voctoria: Public Record Office Victoria.

xiii. $\quad$ Rozner, S., 2013. Developing and Using Key Performance Indicators, AToolkit for Health Sector Managers. Bethesda, MD: Health Finance \& Governance Project. Bethesda: Associates Inc. Scott Stewart, AOR. Office of Health Systems.

xiv. Saudi Arabia Government, 2015. Saudi Arabia Record Budget for 2015. [Online] Available at: https://www.gov.uk/government/publications/saudi-arabia-record-budget-for2015/saudi-

xv. Takim, R. \& Akintoye, A., 2002. Performance indicators for successful construction project perfomance. Ulster, Association of Researchers in Construction Management.

xvi. Wang, W., 2004. A Study of Constructing Performance Indicator System. [Online] Available at: http://www.manage.org.cn

[Accessed 6 November 2009].

xvii. Wikipedia, n.d. Edu Wave. [Online]

Available at: https://en.wikipedia.org/wiki/EduWave

xviii. World Development Indicators (WDI), 2007. Booz \& Company Ideation Center analysis, s.l.: World Development Indicators (WDI).

xix. Wu, C. \& Chen, R. J., 2014. A study on Key Performance Indicators (KPIs) for Basic Education in Taiwan, Taiwan: National Academy for Educational Research. 


\section{APPENDIX}

\section{Form1 : The Survey}

1. How many hours do you usually spend on working with the performance indicator requirements (daily)?

2-3 hours 3-4 hours 4-5 hours

2. Do you think the system focuses on the development of performance concerning teachers/ directors/ supervisors?
Yes
no
I don `t know

3. What percentage of progress added to the performance of your employees after applying the system (performance indicators)?
20-30\%
$40-50 \%$
$60-70 \%$

4. How many hours do you usually spend working on the website Noor (daily)?
1-2 hours
3-4 hours
4-5 hours

5. If the (performance indicators) system was connected to Noor website, how many hours are approximately needed to complete a regular day work in your opinion?

Less than one hour 1-2 hours 3-4 hours

6 . How would you rate your performance indicators before the new implementation?
I have no information
$10-20 \%$
$30-40 \%$

7. Have you been trained adequately before applying the performance indicators?

No yes not enough

8. Do you consider your computer literacy as perfect?
Yes
no
slightly

9. Have you ever used the website Noor?

Yes

no

10. Rate the Internet in your work environment?

Excellent Very good Good Low

11. What benefit do you think of in linking the (performance indicators) system with Noor website?

Time saving Productivity increase Environment protection All the previous answers

12. What are the main three difficulties you faced when applying the (performance indicators) system?

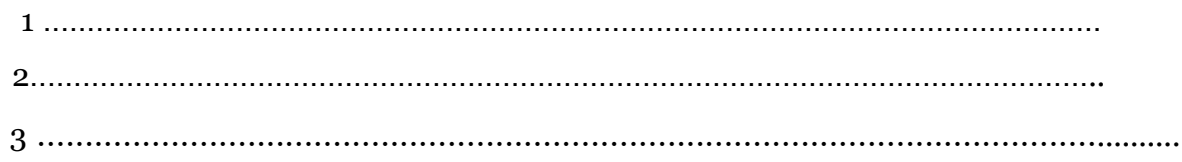

Form3 


\section{Asia Pacific Journal of Advanced Business and Social Studies}

ISBN (eBook): 9780994365675 | ISSN : 2205-6033

Year: 2017, Volume: 3, Issue: 2

Educational supervisor performance indicator model- first semester - academic year 1435/1436

The number of assigned teachers:

the total number of teachers in the section:

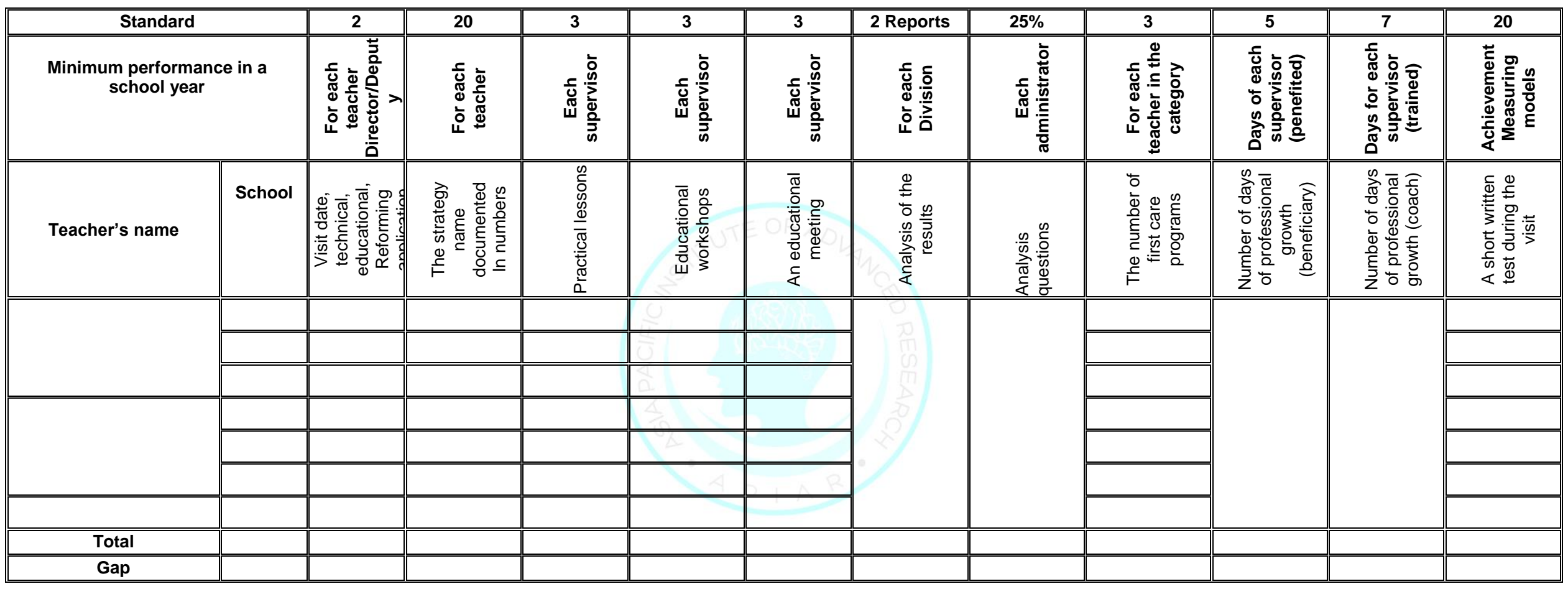

$\prod_{\substack{0 \\ 0 \\ 0 \\ 0}}$ 
Asia Pacific Journal of Advanced Business and Social Studies

ISBN (eBook): 9780994365675 I ISSN : 2205-6033

Year: 2017, Volume: 3, Issue: 2

Form4

\begin{tabular}{|c|c|c|c|c|c|c|c|c|c|c|c|}
\hline Standard & & & & & & & $25 \%$ & & & & \\
\hline $\begin{array}{l}\text { Minimum performance in school } \\
\text { year }\end{array}$ & 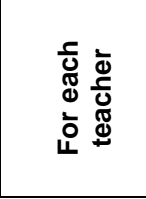 & 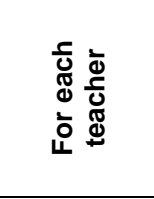 & 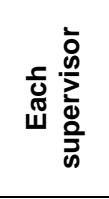 & 童高 & 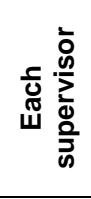 & 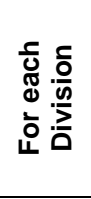 & 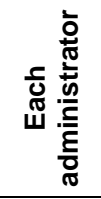 & 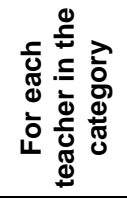 & 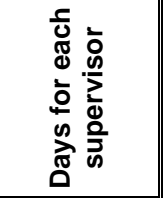 & 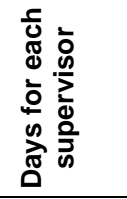 & 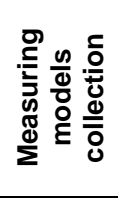 \\
\hline Name of supervisor & 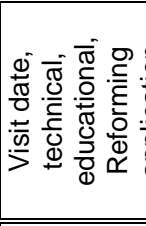 & 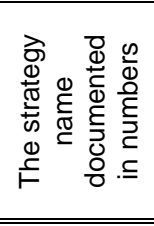 & 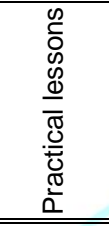 & 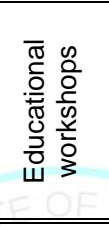 & 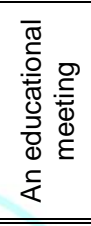 & 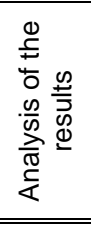 & 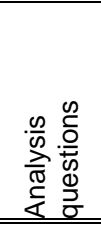 & 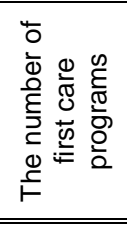 & 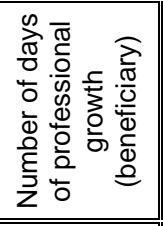 & 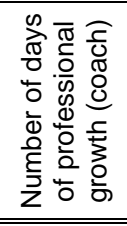 & 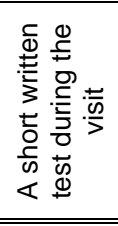 \\
\hline & & & 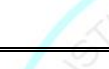 & & 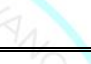 & & & & & & \\
\hline & & & & & & & & & & & \\
\hline & & & & & & & & & & & \\
\hline & & & & & & & & & & & \\
\hline & & & & & & & & & & & \\
\hline Total & & & & & & & & & & & \\
\hline Gap & & & & & & & & & & & \\
\hline
\end{tabular}

Weekly Summary for performance index section

$m$
$m$
0
0
0
0 